\title{
Transition experiences and health care utilization among young adults with type I diabetes
}

\author{
This article was published in the following Dove Press journal: \\ Patient Preference and Adherence \\ 8 August 2013 \\ Number of times this article has been viewed
}

\author{
Katharine C Garvey' \\ Jonathan A Finkelstein ${ }^{2,3}$ \\ Lori M Laffel ${ }^{1,4}$ \\ Victoria Ochoa' \\ Joseph I Wolfsdorf' \\ Erinn T Rhodes' \\ 'Division of Endocrinology, Boston \\ Children's Hospital, ${ }^{2}$ Division of \\ General Pediatrics, Boston Children's \\ Hospital, ${ }^{3}$ Department of Population \\ Medicine, Harvard Pilgrim Health \\ Care Institute, ${ }^{4}$ Pediatric, Adolescent \\ and Young Adult Section, Joslin \\ Diabetes Center, Boston, MA, USA
}

Correspondence: Katharine C Garvey Division of Endocrinology, Boston Children's Hospital, 300 Longwood Avenue, Boston, MA 02115, USA Tel +l 6179193045

Email katharine.garvey@childrens. harvard.edu
Background: The purpose of this study was to describe the current status of adult diabetes care in young adults with type 1 diabetes and examine associations between health care transition experiences and care utilization.

Methods: We developed a survey to assess transition characteristics and current care in young adults with type 1 diabetes. We mailed the survey to the last known address of young adults who had previously received diabetes care at a tertiary pediatric center.

Results: Of 291 surveys sent, 83 (29\%) were undeliverable and three (1\%) were ineligible. Of 205 surveys delivered, 65 were returned (response rate 32\%). Respondents (mean age $26.6 \pm 3.0$ years, $54 \%$ male, $91 \%$ Caucasian) transitioned to adult diabetes care at a mean age of $19.2 \pm 2.8$ years. Although $71 \%$ felt mostly/completely prepared for transition, only half received recommendations for a specific adult provider. Twenty-six percent reported gaps exceeding six months between pediatric and adult diabetes care. Respondents who made fewer than three diabetes visits in the year prior to transition (odds ratio [OR] 4.5, 95\% confidence interval $[\mathrm{CI}] 1.2-16.5$ ) or cited moving/relocation as the most important reason for transition (OR 6.3, 95\% CI 1.3-31.5) were more likely to report gaps in care exceeding six months. Patients receiving current care from an adult endocrinologist $(79 \%)$ were more likely to report at least two diabetes visits in the past year (OR 6.0, 95\% CI 1.5-24.0) compared with those receiving diabetes care from a general internist/adult primary care doctor (17\%). Two-thirds $(66 \%)$ reported receiving all recommended diabetes screening tests in the previous year, with no difference according to provider type.

Conclusion: In this sample, transition preparation was variable and one quarter reported gaps in obtaining adult diabetes care. Nevertheless, the majority endorsed currently receiving regular diabetes care, although visit frequency differed by provider type. Because locating patients after transition was incomplete, our findings suggest the need for standardized methods to track transitioning patients.

Keywords: type 1 diabetes mellitus, health care delivery, young adults, transition to adult care

\section{Introduction}

Health care transition has been defined as "the planned, purposeful movement of young adults from child-centered to adult-oriented health-care systems". ${ }^{1}$ In 2002, a consensus statement from the American Academy of Pediatrics, the American Academy of Family Physicians, and the American College of Physicians underscored the importance of a planned and facilitated health care transition for adolescents with special health care needs. ${ }^{2}$ Unfortunately, updated guidelines in 2011 described inadequate implementation of transition care over the intervening years and reiterated the importance of transition coordination as a basic standard of high-quality care. ${ }^{3}$ 
Type 1 diabetes is a chronic disease that requires complex daily self-management and medical decisionmaking and is an important model for the study of health care transition. The developmental period of emerging adulthood is rife with competing educational, social, and emotional priorities. ${ }^{4}$ In young adults with type 1 diabetes, as in young adults with many other chronic health conditions, such developmental priorities are compounded by intensive self-care requirements. The transition to a new adult care system adds still further challenges. ${ }^{5,6}$ Young adults with type 1 diabetes are at risk for gaps in medical follow-up and adverse diabetes-related outcomes, including poor glycemic control, acute complications, emergence of chronic diabetes complications, and early mortality. ${ }^{7-12}$

The American Diabetes Association recently published expert consensus guidelines on health care transition for emerging adults with diabetes, ${ }^{5}$ but empiric data remain limited. Previous research has demonstrated difficulties in the transition process, including delays in care, ${ }^{13-17}$ increased post-transition diabetes-related hospitalizations,${ }^{18}$ and patient dissatisfaction with transition. ${ }^{13-17}$

To design interventions to improve transition outcomes, it is necessary to understand the transition experiences from the perspective of young adults who have been through the process. Previous work has examined perceptions of health care transition in young adults who have successfully established care at specialty adult diabetes centers. ${ }^{14}$ However, little information is available about the transition experiences, disposition, and current medical care from the perspective of patients who have transferred from pediatric diabetes clinics.

Therefore, our objectives were: to describe the current status of care (type of medical provider, frequency of visits) and quality of care (receipt of recommended screening tests) in post-transition young adults with type 1 diabetes who had previously received pediatric diabetes care at a single tertiary pediatric center; to evaluate associations between health care transition characteristics (eg, gaps between pediatric and adult care, transition preparation) and the current status of care; and to evaluate associations between current diabetes care and health-related quality of life.

\section{Materials and methods Subjects}

Eligible subjects included emerging adults with type 1 diabetes, who had been previously followed in the pediatric diabetes clinic at Boston Children's Hospital. Criteria for eligibility included: at least one diabetes clinic encounter with International Classification of Diseases, Ninth Revision, Clinical Modification (ICD-9-CM) codes 250.X1 or 250.X3 (where $X=0$ through 9) between June 2000 and May 2010; age at least 15 years at the last diabetes clinic visit; and not seen in the 18 months prior to May 2010. To exclude cystic fibrosis-related diabetes, subjects with coexisting ICD-9-CM code 277.0X (cystic fibrosis) were excluded. The study was approved by the institutional review board at Boston Children's Hospital.

\section{Survey instrument}

We developed a survey to assess the transition experiences of patients with type 1 diabetes. Initial survey development was based upon review of the academic health care transition literature in type 1 diabetes and other pediatric chronic illnesses, as well as an Internet search for resources on health care transition. We also utilized qualitative data obtained from focus groups of young adults with type 1 diabetes. ${ }^{19}$ Experts in pediatric and adult diabetes care and health care transition reviewed the instrument for content validity. Pretesting of the final version was performed using six young adults with type 1 diabetes.

The survey was divided into six sections: medical history; attributes of current diabetes care (eg, type of adult medical providers seen and visit frequency); health care transition (eg, reasons for transition, transition preparation and satisfaction, gaps in care); current diabetes self-care practices and social support; health-related quality of life; and demographics. A secure electronic version of the survey was created using a Research Electronic Data Capture (REDCap) survey ${ }^{20}$ hosted by Boston Children's Hospital. The complete survey is available upon reader request.

This survey was developed concurrently with a second survey fielded in a different population of post-transition young adults with diabetes who were known to be receiving care at a single adult diabetes clinic. ${ }^{14}$ There was no overlap in subjects between the two studies. Because subjects in this study had left their pediatric center and current adult care status was unknown, this survey included unique items related to location, type, and quality of current medical care.

For transition preparation, we asked yes/no questions about receipt of eight key preparation elements as well as a summary preparation question (response options: completely unprepared, mostly unprepared, neutral, mostly prepared, and completely prepared). We also included a parallel summary question about satisfaction with transition. We examined self-reported gap between last pediatric diabetes appointment and first adult diabetes appointment 
(response options: $\leq 3$ months, 4-6 months, 7-12 months, 13-24 months, or $>24$ months).

To understand current care patterns, we asked, "Have you ever seen any of the following types of adult medical care providers for your diabetes?", listing endocrinologist, diabetes educator, internist/primary care physician, dietitian, or other; and how many times the subject had seen each of these providers in the past 12 months. We then asked subjects to specify the person they identified as the primary provider of their diabetes care.

The survey asked for self-reporting of most recent glycosylated hemoglobin $\left(\mathrm{HbA}_{1 \mathrm{c}}\right)$ levels, with seven response categories, ie, $\leq 7.0 \%, 7.1 \%-8.0 \%, 8.1 \%-9.0 \%, 9.1 \%-10.0 \%$, $10.1 \%-12 \%,>12 \%$, or "don't know". We asked subjects to report their most recent diabetes screening tests, including separate items for each of the following: blood tests to measure cholesterol and thyroid function; urine tests (microalbumin) to assess kidney status; and an eye examination to check for effects of diabetes on the retina. Response categories for the screening tests included $<12$ months ago, 1-2 years ago, $>2$ years ago, never, or "don't know".

Health-related quality of life was measured using the Duke Health Profile (DUKE), ${ }^{21}$ a 17-item instrument containing six health measures (physical, mental, social, general, perceived health, and self-esteem), for which acceptable levels of reliability and validity have been demonstrated for adults as well as adolescents. ${ }^{22}$

\section{Survey administration}

We mailed the survey in three waves from October to December 2010 to the last known address in the Boston Children's Hospital records. The first mailing included a small gift (sticky notes) and respondents were entered into a raffle to win an Apple iPad $2^{\circledR}$. After completing the three mail waves, we offered the remaining eligible subjects $(69 \%$ of sample) a final opportunity to complete an abbreviated survey electronically that omitted the health-related quality of life module. Because email addresses for subjects were not available, we mailed a letter with a web link for the abbreviated electronic version of the survey and included a \$2 bill. To maximize the response rate, the survey was anonymous and no self-identifying information was collected. Subjects returned a separate identifier postcard to report survey completion for the raffle.

\section{Statistical analysis}

All statistical analyses were conducted using SAS version 9.2 (SAS Institute Inc, Cary, NC, USA). An alpha of 0.05 (two-tailed) was used for statistical significance. Descriptive statistics were calculated as means and standard deviations or proportions. We used Fisher's exact test or bivariate logistic regression to evaluate associations between transition characteristics and current diabetes care patterns, where appropriate. Due to the small sample size, we did not perform multivariable analyses.

Questions about overall transition preparation and satisfaction as well as current perceived success in diabetes management were analyzed as dichotomous variables (combining "mostly" and "completely") to distinguish subjects reporting positive experiences.

Gaps between pediatric and adult diabetes care were also analyzed as a dichotomous variable of up to six months or more than six months. This dichotomization was selected a priori, to allow comparison with other reports, ${ }^{14,16,17,23}$ and given the American Diabetes Association recommendation that insulin-treated patients older than 18 years have diabetes visits at least every six months. ${ }^{24}$

In bivariate analyses, responses for adult clinic visit frequency were analyzed for at least two visits in the past year, and "receipt of all recommended screening tests" was defined as report of blood tests for cholesterol and thyroid, urine tests for microalbumin, and retinal examination in the previous year.

For health-related quality of life, we examined the physical health, mental health, social health, and general health scales on the DUKE $(0=$ poorest and $100=$ best health status). We used Wilcoxon rank-sum tests to explore associations between scale scores and current diabetes care patterns (visit frequency, self-reported $\mathrm{HbA}_{1 \mathrm{c}}$, and perceived success in diabetes management).

\section{Results}

We mailed surveys to the last known mailing address of 291 former patients based on the above criteria. Eighty-three surveys (29\%) were returned to sender. Three subjects were found to be ineligible (one deceased, two miscoded as having type 1 diabetes). From 205 eligible subjects, 65 surveys were returned (56 paper surveys from waves $1-3$ and nine electronic surveys from the final wave 4$)$. The overall response rate was $32 \%(65 / 205)$.

\section{Sample characteristics}

Table 1 displays subject characteristics. The mean age of the respondents was $26.6 \pm 3.0$ years and the mean age at onset of diabetes was $9.7 \pm 3.2$ years. The majority were male (54\%), Caucasian (91\%), college-educated (64\%), employed 
Table I Demographic and clinical characteristics of respondents

\begin{tabular}{|c|c|c|}
\hline Characteristic & $\begin{array}{l}\text { Observed Sample } \\
\text { Size (n) }\end{array}$ & $\begin{array}{l}\text { Mean } \pm \text { SD } \\
\text { or } \%\end{array}$ \\
\hline Current age & 65 & $26.6 \pm 3.0$ years \\
\hline Male & 65 & $54 \%$ \\
\hline Race & 65 & \\
\hline White/Caucasian & & $91 \%$ \\
\hline Black/African-American & & $5 \%$ \\
\hline Asian/Pacific Islander & & $4 \%$ \\
\hline Highest level of education & 63 & \\
\hline High school or equivalent & & $11 \%$ \\
\hline Some college & & $25 \%$ \\
\hline Four-year college degree & & $32 \%$ \\
\hline Some graduate school & & $8 \%$ \\
\hline Graduate degree & & $24 \%$ \\
\hline Health insurance & 64 & \\
\hline Private insurance & & $77 \%$ \\
\hline Public insurance & & $23 \%$ \\
\hline \multicolumn{3}{|l|}{ Diabetes history } \\
\hline Age at diabetes diagnosis & 59 & $9.7 \pm 3.2$ years \\
\hline $\begin{array}{l}\text { Most recent } \mathrm{HbA} \\
\text { (self-reported) }\end{array}$ & 62 & \\
\hline$\leq 7.0 \%$ & & $25 \%$ \\
\hline $7.1 \%-8.0 \%$ & & $34 \%$ \\
\hline $8.1 \%-9.0 \%$ & & $31 \%$ \\
\hline $9.1 \%-10.0 \%$ & & $3 \%$ \\
\hline $10.1 \%-12.0 \%$ & & $6 \%$ \\
\hline$>12.0 \%$ & & $0 \%$ \\
\hline Don't know & & $1 \%$ \\
\hline Comorbidities & 65 & \\
\hline Diabetic retinopathy & & $3 \%$ \\
\hline Hypercholesterolemia & & $8 \%$ \\
\hline Hypertension & & $6 \%$ \\
\hline Depression & & $11 \%$ \\
\hline Anxiety & & $11 \%$ \\
\hline \multicolumn{3}{|l|}{ Health care delivery } \\
\hline $\begin{array}{l}\text { Age at transition to adult } \\
\text { diabetes care }\end{array}$ & 60 & $19.2 \pm 2.8$ years \\
\hline Gap between last pediatric & 61 & \\
\hline \multicolumn{3}{|l|}{ diabetes visit and first adult visit } \\
\hline$\leq 3$ months & & $28 \%$ \\
\hline 4-6 months & & $46 \%$ \\
\hline $7-12$ months & & $20 \%$ \\
\hline$>12$ months & & $6 \%$ \\
\hline \multicolumn{2}{|l|}{ provider } & \\
\hline Adult endocrinologist & & $79 \%$ \\
\hline Internist/primary care & & $17 \%$ \\
\hline Nurse practitioner/diabetes & & $2 \%$ \\
\hline educator & & \\
\hline Other & & $2 \%$ \\
\hline $\begin{array}{l}\text { Receipt of all recommended } \\
\text { diabetes screening tests } \\
\text { in past year }\end{array}$ & 62 & $66 \%$ \\
\hline
\end{tabular}

Abbreviations: $\mathrm{SD}$, standard deviation; $\mathrm{HbA}_{\mathrm{lc}}$, glycosylated hemoglobin.

full-time (56\%), and had private insurance (77\%). Twenty-nine percent were living with their parents and a third of respondents described their parents as moderately or very involved in their diabetes care. Overall, $69 \%$ felt mostly or completely successful in diabetes self-management.
Twenty-five percent of subjects reported a most recent $\mathrm{HbA}_{1 \mathrm{c}}$ level in the American Diabetes Association target range $(\leq 7.0 \%)$ while $40 \%$ reported $\mathrm{HbA}_{1 \mathrm{c}}$ levels $>8.0 \%$.

Those who did not respond to the survey (including undeliverable surveys as well as nonrespondents) were $59 \%$ male ( $P=0.55$ for comparison with respondents) and had a mean age of $25.9 \pm 3.8$ years $(P=0.19)$. No other data were available for comparison between respondents and nonrespondents.

\section{Transition characteristics}

The mean age at transition was $19.2 \pm 2.8$ years. The top three reasons for transition endorsed as "most important" included pediatric provider suggestion (29\%), feeling "too old" for pediatrics (25\%), and moving (15\%). Overall, $71 \%$ felt mostly or completely prepared for transition, and $68 \%$ felt mostly or completely satisfied with their transition experience. Perception of overall preparation and satisfaction were highly associated $(P<0.0001)$.

Figure 1 shows the report of eight specific pediatric transition preparation activities as well as the perceived importance of each one in facilitating a successful transition. More than $50 \%$ of respondents reported receiving three of these items (having a pediatric diabetes visit without a parent/ guardian in the room, discussing annual diabetes screening tests, and discussing independent diabetes self-management). Approximately one half of respondents received a specific recommendation for an adult provider or clinic, while more than $80 \%$ felt that these recommendations were important. Less than $15 \%$ had a specific transition visit, received written transition materials, or met the new adult provider before transition, while $36 \%-51 \%$ felt that these items were important.

Twenty-six percent of respondents reported a gap of more than six months between the last pediatric diabetes visit and the first adult visit, and $6 \%$ reported a gap of more than 12 months (Table 1). In bivariate logistic models, respondents (46\%) who had fewer than three pediatric diabetes visits in the year prior to transition (odds ratio [OR] 4.5, 95\% confidence interval [CI] 1.2-16.5) and those who cited moving/relocation as the most important reason for transition (OR 6.3, 95\% CI 1.3-31.5) were significantly more likely to report gaps between pediatric and adult care of more than six months. Twenty-three percent of those who felt mostly/completely prepared for transition reported gaps in care, while $35 \%$ of those who felt neutral or unprepared reported gaps in care; this difference did not reach statistical significance (OR 0.5, 95\% CI 0.2-1.8).

\section{Delivery of adult care}

Overall, $80 \%$ of subjects had seen their main adult diabetes doctor at least twice in the previous year. The frequency of 


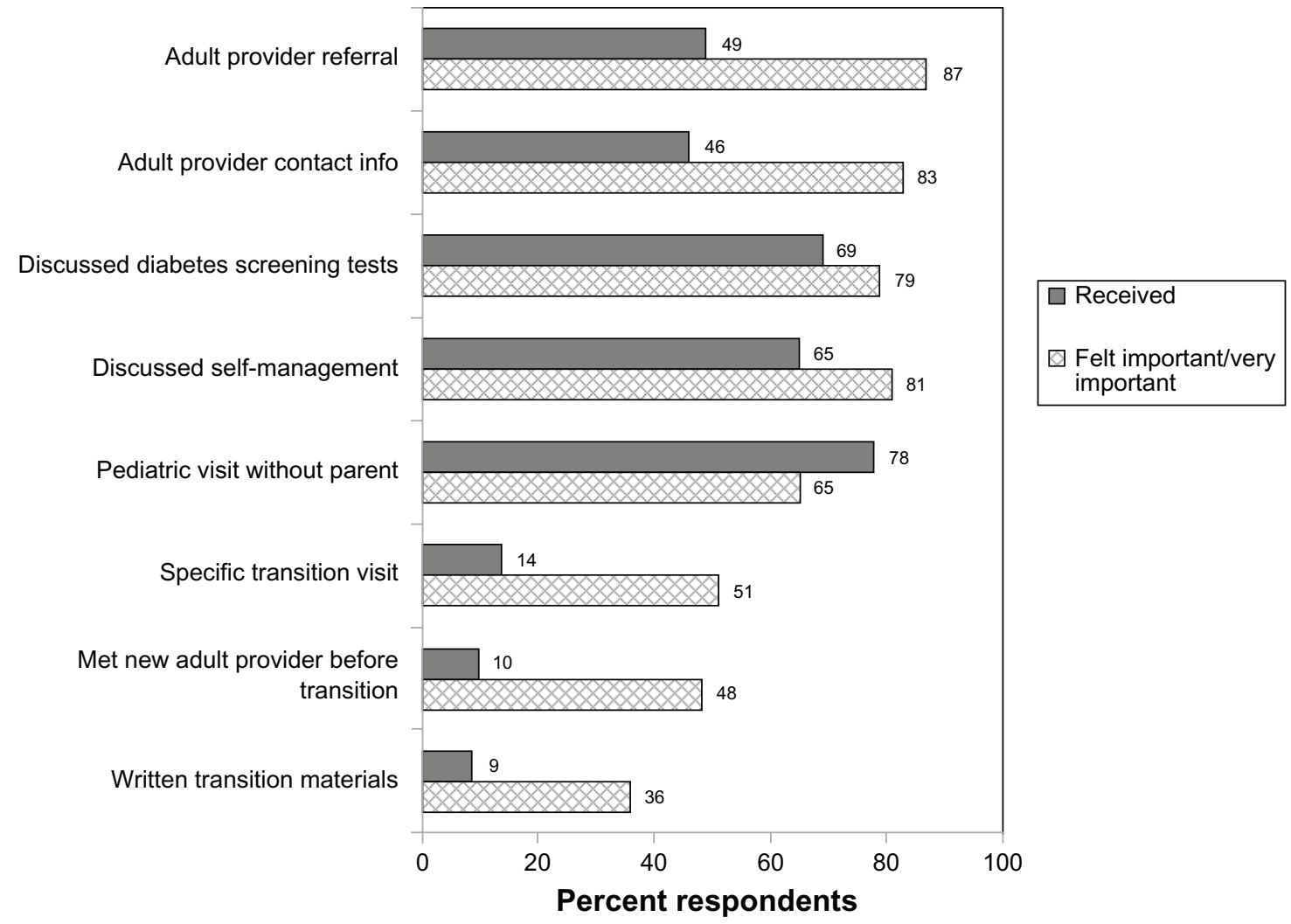

Figure I Solid bars represent proportions of respondents who reported receiving specific transition preparation items. Cross-hatched bars represent proportions of respondents who felt that receipt of each item was important or very important in the transition process.

adult diabetes visits in the previous year was not significantly lower in subjects who felt unprepared for transition (OR for at least two adult diabetes visits in the past year $0.5,95 \%$ CI 0.1-1.8) or who reported gaps in care of more than six months (OR 0.4, 95\% CI 0.1-1.8).

Seventy-nine percent of respondents identified an adult endocrinologist as the current main diabetes provider, while $17 \%$ identified an adult primary care doctor or internist, $2 \%$ reported a nurse practitioner, and $2 \%$ reported another provider (Table 1). Eighty-eight percent of those identifying an endocrinologist as the main diabetes provider reported at least two diabetes visits in the past year, compared with $54 \%$ of those identifying an internist or other types of diabetes providers. Compared with the rest of the sample, those identifying an adult endocrinologist as the main diabetes provider were six times more likely to report more than two diabetes visits in the past year (OR 6.0, 95\% CI 1.5-24.0). Self-reported glycemic control and satisfaction with current adult diabetes care did not differ by visit frequency or type of main diabetes provider.

Regarding annual screening for diabetes complications, $66 \%$ of respondents reported receiving all of the recommended tests in the preceding year; $84 \%$ of all respondents had received an eye examination for retinopathy. Less than
$3 \%$ reported "don't know" for each screening test frequency, except for thyroid function testing $(9 \%)$. Report of screening tests in the previous year did not differ by visit frequency or type of main diabetes provider.

\section{Health-related quality of life}

Health-related quality of life data were available for 53 subjects. Overall, mean DUKE scores for physical, mental, social, and general health were high $(82.1 \pm 17.2,79.2 \pm 19.4$, $78.5 \pm 19.9$, and $79.9 \pm 14.3$, respectively), comparable with or higher than scores reported in a general population of adolescents and young adults..$^{22}$ General health scores did not differ significantly by gender, type of primary diabetes provider, visit frequency, self-reported $\mathrm{HbA}_{1 \mathrm{c}}$, or perceived success in diabetes self-management.

\section{Discussion}

This study offers a paradigm for assessment of the health care transition experience and post-transition health care of young adults with type 1 diabetes. Our study complements prior studies elucidating key challenges in type 1 diabetes transition. We contribute the perspective of patients previously cared for at a pediatric diabetes clinic in a US tertiary pediatric center. 
In this sample, post-transition health care delivery reports were promising in that the vast majority of respondents were receiving regular adult diabetes care, with $75 \%$ reporting at least two diabetes visits in the previous year. These rates of follow-up are significantly higher than those published in observational studies in Europe, ${ }^{15,25}$ but analogous posttransition data for comparison are limited in the US.

Interestingly, the high rates of follow-up reported in this sample occurred despite lower reports of transition preparation. For instance, less than half of patients received specific adult provider referral names or contact information, and yet the vast majority of respondents $(>80 \%)$ felt that these were important aspects of transition. Our findings are consistent with other reports of nonpurposeful transitions in type 1 diabetes. ${ }^{13-15,26}$ More broadly, deficits in preparation for transition have been described in large national surveys of young adults with a mix of chronic health conditions, ${ }^{27,28}$ as well as in patients with single diagnoses associated with intensive daily self-management requirements, such as cystic fibrosis $^{29}$ and complex health screening recommendations, such as Turner syndrome. ${ }^{30}$

Gaps between pediatric and adult diabetes care may be detrimental to long-term diabetes outcomes, especially given the known associations between infrequent clinic follow-up and the occurrence of acute and chronic diabetes complications in youth with type 1 diabetes., ${ }^{9,31}$ One quarter of our respondents reported a gap of more than six months between pediatric and adult care, a figure consistent with several other studies. ${ }^{14,16,17,32}$ Respondents with fewer than three pediatric visits in the year prior to transition and those who cited relocation/moving as the main impetus for transition were more likely to report gaps in care. Transition coordination programs in Canada and Australia have shown reduced care gaps for patients with type 1 diabetes. ${ }^{23,33}$ Our findings suggest a possible role for targeted transition care referrals and tracking for those patients who are relocating. In particular, our high survey nonresponse underscores the potential important role of tracking programs to ensure follow-up of patients once they leave their pediatric care.

A priori, we had planned to examine relationships between transition characteristics (preparation, gaps between pediatric and adult care) and current adult care patterns (in particular visit frequency). However, because the majority of respondents in our sample were receiving regular diabetes care with at least two visits in the past year as per American Diabetes Association guidelines, we did not have sufficient numbers of respondents to explore this question fully. We found that patients identifying an adult endocrinologist as their main diabetes provider were significantly more likely to report regular diabetes clinic visits compared with those identifying general internists or others as the main diabetes provider. This finding did not translate into differences in screening test patterns or reported glycemic control, although small numbers may have limited our ability to detect differences in these outcomes.

Our findings regarding provider characteristics are consistent with the multicenter, population-based SEARCH for Diabetes in Youth Study, which showed that $70 \%$ of 363 subjects $\geq 18$ years of age (mean age $21.2 \pm 2.3$ years) were seeing a diabetes specialist (25\% reported a pediatric endocrinologist and $45 \%$ an adult endocrinologist) while $17 \%$ were seeing a generalist. Subjects seeing a generalist were significantly less likely to report receipt of recommended diabetes screening tests compared with those seeing an endocrinologist. ${ }^{34}$ Variation in the nature and quality of diabetes care from different types of adult providers requires further study, and transition preparation may need to be tailored to the type of adult provider a patient will be seeing following transfer. Additionally, continuing medical education about young adult diabetes care should be targeted to general internists and family physicians as well as adult endocrinologists.

Several limitations of this study must be noted. The cross-sectional design prevents assertions about causality. The survey instrument was new, which could impact the validity of responses, although we developed the items based on literature review, qualitative data from focus groups, and expert input. There is evidence in the literature of concordance between self-reported survey data and medical record data for outpatient diabetes care, ${ }^{35,36}$ but our self-reported survey data are nonetheless potentially subject to recall and social desirability biases. Further, the study design could not include any validation of respondent data from pediatric or adult medical records.

Nonresponse bias is also a concern; the response rate was suboptimal, although comparable at 32\% with other post-transition diabetes studies. ${ }^{16,37}$ While the age and gender distribution of the nonrespondents and respondents was similar, no other data were available for nonrespondents. The respondent sample was further impacted by the use of the last known mailing address in recruitment, which may have biased the sample towards people still connected with medical care near their childhood homes. Finally, the small sample size limited our ability to conduct multivariable analyses and to control for confounders such as socioeconomic status. Despite these limitations, our findings are consistent 
with previous publications and provide contemporary information from emerging young adults who transferred from pediatric care solely within a children's facility to adult care providers.

Our respondent sample was, on average, a highly educated, relatively advantaged group of patients, most of whom were currently receiving regular diabetes care. As in other studies of youth with type 1 diabetes, health-related quality of life was generally high. ${ }^{38,39}$ Many of our observations are encouraging regarding the follow-up care of youth with type 1 diabetes following their transfer to adult providers, but given the relatively low response rate, our findings may represent a "best-case" scenario. All of the respondents had some type of health insurance, due to extremely high rates of health insurance in Massachusetts that are not representative of the current landscape throughout the US. Therefore, we were not able to evaluate associations between health insurance and transition care utilization. Previous research has pointed to disparities in the transition process for youth with childhood-onset chronic illness from more diverse patient samples, including the underinsured. ${ }^{40}$ The challenges in transition identified in this study would likely be magnified in more diverse young adult populations, and this remains a key area for future research.

Finally, 28\% of our surveys were returned to sender, which represents an important finding. It is difficult to track young adults in a mobile society after they leave a pediatric center, and, as other studies have found, this difficulty increases with each passing year after transition. ${ }^{37}$ This is not diabetes-specific, and is an area of concern for the care of emerging adults. The US health care transition consortium "Got Transition" has put forth six core practice elements (www.gottransition.org) based on expert consensus, one of which is clinic-based registries to follow transitioning youth. Our results support the need to create patient registries to track the follow-up of transitioning patients as well as the utility of prospective research to facilitate understanding of transition outcomes. ${ }^{41}$

\section{Conclusion}

Our findings highlight the importance of operationalizing the transition process to improve patient satisfaction and health outcomes among emerging adults with type 1 diabetes. This study utilized a survey instrument that other investigators and programs may use to evaluate transition characteristics and adult care patterns in their patients with type 1 diabetes and which can be adapted to the study of other chronic pediatric illnesses. Systematic prospective assessment of transition and post-transition variables will be important in studying the impact of future interventions aimed at making transition preparation more purposeful.

\section{Acknowledgments}

This study was funded by a grant from the Program for Patient Safety and Quality at Boston Children's Hospital. KCG was supported by the Agency for Healthcare Research and Quality (T32-HS000063), the National Institute of Diabetes and Digestive and Kidney Diseases (T32DK007699-30), the National Institute for Diabetes and Digestive and Kidney Diseases (K12-DK094721), and the William Randolph Hearst Foundation. JAF's work on this project was funded by a grant from the National Institute for Child Health and Human Development (K24-HD060786). LL's work on this project was funded by a grant from the National Institute for Diabetes and Digestive and Kidney Diseases (K12-DK094721). A portion of this study was presented in abstract form at the International Society for Pediatric and Adolescent Diabetes 37th Annual Meeting, October 19-22, 2011, Miami, Florida.

\section{Author contributions}

$\mathrm{KG}$ designed the study, developed the survey, collected data, analyzed data, and wrote and reviewed/edited the manuscript. JF participated in the study design and survey development, contributed to discussion, and reviewed/ edited the manuscript. LL participated in data analysis, contributed to the discussion, and reviewed/edited the manuscript. VO participated in data collection, contributed to discussion, and reviewed/edited the manuscript. JW participated in the study design and survey development, contributed to discussion, and reviewed/edited the manuscript. ER designed the study, participated in survey development, participated in data collection and analysis, and reviewed/edited the manuscript. All authors read and approved the final manuscript.

\section{Disclosure}

None of the authors have any competing interests relevant to this study to report.

\section{References}

1. Blum RW, Garell D, Hodgman CH, et al. Transition from child-centered to adult health-care systems for adolescents with chronic conditions. A position paper of the Society for Adolescent Medicine. J Adolesc Health. 1993;14:570-576.

2. American Academy of Pediatrics, American Academy of Family Physicians, and American College of Physicians-American Society of Internal Medicine. A consensus statement on health care transitions for young adults with special health care needs. Pediatrics. 2002;110:1304-1306. 
3. Cooley WC, Sagerman PJ. Supporting the health care transition from adolescence to adulthood in the medical home. Pediatrics. 2011;128: $182-200$.

4. Arnett JJ. Emerging adulthood. A theory of development from the late teens through the twenties. Am Psychol. 2000;55:469-480.

5. Peters A, Laffel L. Diabetes Care for Emerging Adults: Recommendations for Transition From Pediatric to Adult Diabetes Care Systems: a position statement of the American Diabetes Association, with representation by the American College of Osteopathic Family Physicians, the American Academy of Pediatrics, the American Association of Clinical Endocrinologists, the American Osteopathic Association, the Centers for Disease Control and Prevention, Children with Diabetes, the Endocrine Society, the International Society for Pediatric and Adolescent Diabetes, Juvenile Diabetes Research Foundation International, the National Diabetes Education Program, and the Pediatric Endocrine Society (formerly Lawson Wilkins Pediatric Endocrine Society). Diabetes Care. 2011;34:2477-2485.

6. Weissberg-Benchell J, Wolpert H, Anderson BJ. Transitioning from pediatric to adult care: a new approach to the post-adolescent young person with type 1 diabetes. Diabetes Care. 2007;30: 2441-2446.

7. Bryden KS, Dunger DB, Mayou RA, Peveler RC, Neil HA. Poor prognosis of young adults with type 1 diabetes: a longitudinal study. Diabetes Care. 2003;26:1052-1057.

8. Bryden KS, Peveler RC, Stein A, Neil A, Mayou RA, Dunger DB. Clinical and psychological course of diabetes from adolescence to young adulthood: a longitudinal cohort study. Diabetes Care. 2001;24: 1536-1540.

9. Jacobson AM, Hauser ST, Willett J, Wolfsdorf JI, Herman L. Consequences of irregular versus continuous medical follow-up in children and adolescents with insulin-dependent diabetes mellitus. J Pediatr. 1997;131:727-733.

10. Laing SP, Jones ME, Swerdlow AJ, Burden AC, Gatling W. Psychosocial and socioeconomic risk factors for premature death in young people with type 1 diabetes. Diabetes Care. 2005;28:1618-1623.

11. Wills CJ, Scott A, Swift PG, Davies MJ, Mackie AD, Mansell P. Retrospective review of care and outcomes in young adults with type 1 diabetes. BMJ. 2003;327:260-261.

12. Lotstein DS, Seid M, Klingensmith G, et al. Transition from pediatric to adult care for youth diagnosed with type 1 diabetes in adolescence. Pediatrics. 2013;131:e1062-e1070.

13. Busse FP, Hiermann P, Galler A, et al. Evaluation of patients' opinion and metabolic control after transfer of young adults with type 1 diabetes from a pediatric diabetes clinic to adult care. Horm Res. 2007;67: $132-138$.

14. Garvey KC, Wolpert HA, Rhodes ET, et al. Health care transition in patients with type 1 diabetes: young adult experiences and relationship to glycemic control. Diabetes Care. 2012;35:1716-1722.

15. Kipps S, Bahu T, Ong K, et al. Current methods of transfer of young people with type 1 diabetes to adult services. Diabet Med. 2002;19: 649-654.

16. Pacaud D, McConnell B, Huot C, Aebi C, Yale J. Transition from pediatric to adult care for insulin-dependent diabetes patients. Can J Diabetes. 1996;20:14-20.

17. Pacaud D, Yale J, Stephure D, Dele-Davies H. Problems in transition from pediatric to adult care in individuals with diabetes. Can J Diabetes. 2005;40:29-35.

18. Nakhla M, Daneman D, To T, Paradis G, Guttmann A. Transition to adult care for youths with diabetes mellitus: findings from a Universal Health Care System. Pediatrics. 2009;124:e1134-e1141.

19. Garvey KC, Wolpert HA, Beste MG, Luff DL, Ritholz MD. Perceptions of health care transition in young adults with type 1 diabetes [abstract]. Diabetes. 2012;61 Suppl 1.

20. Harris PA, Taylor R, Thielke R, Payne J, Gonzalez N, Conde JG. Research electronic data capture (REDCap) - a metadata-driven methodology and workflow process for providing translational research informatics support. J Biomed Inform. 2009;42:377-381.
21. Parkerson GR Jr, BroadheadWE, Tse CK. The Duke Health Profile. A 17-item measure of health and dysfunction. Med Care. 1990;28: 1056-1072.

22. Baumann C, Erpelding ML, Perret-Guillaume C, et al. Health-related quality of life in French adolescents and adults: norms for the DUKE Health Profile. BMC Public Health. 2011;11:401.

23. Van Walleghem N, Macdonald CA, Dean HJ. Evaluation of a systems navigator model for transition from pediatric to adult care for young adults with type 1 diabetes. Diabetes Care. 2008;31:1529-1530.

24. American Diabetes Association. Standards of medical care in diabetes - 2012. Diabetes Care. 2012;35 Suppl 1:S11-S63.

25. Sparud-Lundin C, Ohrn I, Danielson E, Forsander G. Glycaemic control and diabetes care utilization in young adults with type 1 diabetes. Diabet Med. 2008;25:968-973.

26. Dovey-Pearce G, Hurrell R, May C, Walker C, Doherty Y. Young adults' (16-25 years) suggestions for providing developmentally appropriate diabetes services: a qualitative study. Health Soc Care Community. 2005;13:409-419.

27. Kane DJ, Kasehagen L, Punyko J, Carle AC, Penziner A, Thorson S. What factors are associated with state performance on provision of transition services to CSHCN? Pediatrics. 2009;124 Suppl 4: S375-S383.

28. Sawicki GS, Whitworth R, Gunn L, Butterfield R, Lukens-Bull K, Wood D. Receipt of health care transition counseling in the national survey of adult transition and health. Pediatrics. 2011;128:e521-e529.

29. Anderson DL, Flume PA, Hardy KK, Gray S. Transition programs in cystic fibrosis centers: perceptions of patients. Pediatr Pulmonol. 2002;33:327-331.

30. Garvey KC, Finkelstein JA, Wolfsdorf JI, Rhodes ET. Transition from pediatric to adult health care in young women with Turner syndrome [abstract]. Endocr Rev. 2011;32:P2-719. Available from: http://edrv. endojournals.org/cgi/content/meeting_abstract/32/03_MeetingAbstracts/P2-719. Accessed July 3, 2013.

31. Krolewski AS, Warram JH, Christlieb AR, Busick EJ, Kahn CR. The changing natural history of nephropathy in type I diabetes. Am J Med. 1985;78:785-794.

32. Frank M. Factors associated with non-compliance with a medical follow-up regimen after discharge from a pediatric clinic. Can $J$ Diabetes. 1996;20:13-20.

33. Holmes-Walker DJ, Llewellyn AC, Farrell K. A transition care programme which improves diabetes control and reduces hospital admission rates in young adults with type 1 diabetes aged $15-25$ years. Diabet Med. 2007;24:764-769.

34. Waitzfelder B, Pihoker C, Klingensmith G, et al. Adherence to guidelines for youths with diabetes mellitus. Pediatrics. 2011;128:531-538.

35. Fowles JB, Rosheim K, Fowler EJ, Craft C, Arrichiello L. The validity of self-reported diabetes quality of care measures. Int J Qual Health Care. 1999;11:407-412.

36. Tisnado DM, Adams JL, Liu H, et al. What is the concordance between the medical record and patient self-report as data sources for ambulatory care? Med Care. 2006;44:132-140.

37. Neu A, Losch-Binder M, Ehehalt S, Schweizer R, Hub R, Serra E. Follow-up of adolescents with diabetes after transition from paediatric to adult care: results of a 10-year prospective study. Exp Clin Endocrinol Diabetes. 2010;118:353-355.

38. Laffel LM, Connell A, Vangsness L, Goebel-Fabbri A, Mansfield A, Anderson BJ. General quality of life in youth with type 1 diabetes: relationship to patient management and diabetes-specific family conflict. Diabetes Care. 2003;26:3067-3073.

39. Naughton MJ, Ruggiero AM, Lawrence JM, et al. Health-related quality of life of children and adolescents with type 1 or type 2 diabetes mellitus: SEARCH for Diabetes in Youth Study. Arch Pediatr Adolesc Med. 2008;162:649-657.

40. Lotstein DS, Kuo AA, Strickland B, Tait F. The transition to adult health care for youth with special health care needs: do racial and ethnic disparities exist? Pediatrics. 2010;126 Supp1 3:S129-S136.

41. Helgeson VS, Reynolds KA, Snyder PR, et al. Characterizing the transition from paediatric to adult care among emerging adults with type 1 diabetes. Diabet Med. 2013;30:610-615. 
Patient Preference and Adherence

Dovepress

\section{Publish your work in this journal}

Patient Preference and Adherence is an international, peer-reviewed, open access journal focusing on the growing importance of patient preference and adherence throughout the therapeutic continuum. Patient satisfaction, acceptability, quality of life, compliance, persistence and their role in developing new therapeutic modalities and compounds to optimize clinical outcomes for existing disease states are major areas of interest. This journal has been accepted for indexing on PubMed Central. The manuscript management system is completely online and includes a very quick and fair peer-review system. Visit http://www.dovepress.com/ testimonials.php to read real quotes from published authors.

Submit your manuscript here: http://www.dovepress.com/patient-preference-and-adherence-journal 